Öz

1960'larda dijital teknolojilerin mimarlık disiplininde yer almastyla birlikte, bilgisayar destekli tasarım (BDT) araçları hem mimari tasarımları sanal ortamda çizmeye ve modellemeye imkan vermiș, hem de sanal ortamdaki bu temsilleri fiziksel olarak hayata geçirmeye yardımcı olmuştur. Gelişen dijital teknolojiler aynı zamanda işbirlikçi bir süreci desteklemiş ve mimari tasarım sürecinde biçim, malzeme ve taşıyıcıllk bir arada ele alınabilmiștir. Yapı Bilgi

Modelleme (YBM) ise bilgisayar destekli bir araç olmanın ötesine geçerek tasarım, üretim, inşaat ve işletim aşamalarında gerekli olan tüm veriyi içinde barındıran üç boyutlu bir veri modeli olarak, farklı disiplinlerin tasarımdan üretime tüm sürece eşzamanlı dahil olmasını desteklemiş ve bilgi alısverișini daha sağ $l_{1 k} l_{1}$ hale

getirmiştir. Dijital tasarım, dijital yaratma ve üretme süreclerini içeren sürec odaklı bir yapıya dönüşmekte ve bugün dijital mimari tasarım sürecini değerlendirebilmek, taşıııcı sistem tasarımını da anlamay gerektirmektedir.

$\mathrm{Bu}$ çalışmada, taşıyıcı sistem tasarımının dijital mimari tasarım sürecinin bütünleşik bir parçası haline gelmesi, biçim-taşıyıcı sistem-inşa edilebilirlik arasındaki ilişki bağlamında irdelenmiştir. Bu irdelemede, karmaşık geometrilerin tasarımını, analizini ve inşasını olanaklı kılan BDT ve eşzamanlı bir etkilessimi mümkün hale getirerek birlikte işlerliği destekleyen YBM süreçleri, BDT ve YBM'nin inşa edilebilirlik sürecine olan katkısı ve BDT ve YBM ilişkisinde tasarım sürecinin geldiği nokta değerlendirilmektedir. BDT ve YBM'nin mimari tasarım ve taşıyııı sistem tasarımı arasındaki ilişkiye olan etkisi, entegre tasarım süreçlerine sahip örnekler ve bu süreçlerde kullanılan araçlar üzerinden tartışılmışıิır.

\section{Abstract}

With the introduction of digital technologies into architecture discipline in the 1960s, computer-aided design (CAD) tools both allowed architectural designs to be drawn and modeled in a digital environment, and helped to materialise them in physical environment. Digital technologies also supported a collaborative process, and enabled to handle form-material-structure together. Building Information Modeling (BIM), on the other hand, has gone beyond being a computer-aided tool and as a threedimensional data model that contains the data required for design, production, construction and operation stages, supported the simultaneous integration of different disciplines and made information exchange healthier. Digital design is transforming into a process-oriented structure that includes digital creation and production processes, and today, evaluating the digital architectural design process requires understanding of structural design.

In this study, structural design that is becoming an integral part of the digital architectural design process is examined in the context of the relationship between form-

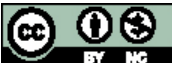

This work is licensed under a Creative Commons Attribution-NonCommerci 4.0 International License.

\title{
Yazılım Teknolojilerinin Kullanildı̆̆ı Mimari Tasarım Süreçlerinde Taşıyıcı Sistem Tasarımı Üzerine Bir inceleme
}

(D) Yelin Demir Altıntaş İzmir Yüksek Teknoloji Enstitüsü, Mimarlık Bölümü

(D) Ülkü Inceköse İzmir Yüksek Teknoloji Enstitüsü, Mimarlık Bölümü

Başvuru tarihi/Received: 09.10.2018, Kabul tarihi/Final Acceptance: 16.01.2019

\section{Giriş}

1960'larda dijital teknolojilerin mimarlık disiplininde yer almasiyla birlikte, bilgisayar destekli araçlar mimari tasarım ve üretim süreçleri için yeni olanaklar sunmuştur. Bilgisayar destekli tasarım ve üretim süreçleri, hem mimari tasarımları sanal ortamda çizmeye ve modellemeye imkan vermiş, hem de sanal ortamdaki bu temsilleri fiziksel olarak hayata geçirmeye yardımc1 olmuştur. Kolarevic'in (2000, s. 98) de vurguladığ 1 gibi gelişen bilgi çağ ${ }_{1}$ sadece ne tasarladığımızı değil, aynı zamanda nasıl tasarladığımızı, tasarım süreçlerini ve arayışlarını da dönüştürmektedir. Gelişen dijital teknolojiler aynı zamanda farklı disiplinlerin iletişimlerinde ve birbirlerine veri aktarım şeklinde de değişikliklere neden olmuştur. Mimari tasarım sürecinde ana biçim kararları alındıktan sonra taşıyıcı sistem tasarımı için mühendisin devreye girebildiği ve bilgisayarların kullanılmadı$\breve{g}_{1}$ geleneksel lineer tasarım süreçlerinden farklı olarak, proje katılımcıları entegre bir süreç içerisinde bilgi alışverişlerini mekan ve zamana bağlı olmaksızın hızlı ve kolay bir şekilde gerçekleştirebilmektedir. Rivka Oxman ve Robert Oxman'in $(2010$, s. 15) da "yeni yapisalc1lık (new structuralism)" olarak tanımladığı mimar ve yapı mühendisleri arasındaki işbirlikçi ilişki, dijital teknolojilerin de desteklemesiyle gelişmiş ve mimari tasarım sürecinde biçim, malzeme ve taşıyıcılık bir arada ele alınabilmiştir.

Tasarımın bilgisayar destekli tasarım ortamlarında ele alınabilmesi, tasarım ve modelleme programlarının çeşitlenmesi ve detaylı modelleme imkanları, mimarların kartezyen geometri ile tanımlanması çok kolay olmayan karmaşık biçimleri kolaylıkla yaratabilmesine imkan vermiştir. Bilgisayar destekli tasarım biçim merkezli tasarım süreçlerini ortaya çıkarmış, karmaşı ve düzensiz biçimlerin dijital mimarinin ayırıcı bir özelliği olduğu literatürde de vurgulanmıştır (Castle, 2010, s. 5; De Luca ve Nardini, 2002; Franken, 2009, s. 121-138; Goulthorpe, 2009, s. 163-180). Fakat, mimarların karmaşık biçimleri özgürce yaratabilme olanakları, mühendisleri estetik ve yapısal gereksinimleri karşılayan ve aynı zamanda bütçenin sınırlarında kalan uygun yapısal çözümler bulma konusunda zorlamıştır (Bagneris, Rene, Bernard ve Nicolas, 2008, s. 79-87). $\mathrm{Bu}$ durum da konvansiyonel dışı biçimlerin inşa edilebilirliğine yönelik çözüm arayışlarında taşıyıcı sistem tasarımının mimari tasarım sürecinin başından itibaren sürece dahil olduğu, etkileşim içinde ilerleyen entegre bir sürecin önemini açıç̣a göstermiştir.

Dijital teknolojilerin işbirlikçi tasarım süreçlerini desteklemesi ve farklı disiplinler arasındaki bilgi alışverişini kolaylaştırması 
structure-constructability. In this examination, CAD that enables design, analysis and construction of complex geometries; BIM that supports interoperability by enabling a simultaneous interaction; the contribution of $C A D$ and BIM to the constructability; and the current state of the design process in the context of $C A D-B I M$ relation are evaluated. The effects of $C A D$ and BIM on architectural designstructural design relationship are discussed through examples designed with integrated design processes and the tools employed.

Anahtar Kelimeler: Bilgisayar destekli mimari tasarım, bilgisayar destekli taşıyıc sistem tasarımı, yapı bilgi modelleme, birlikte işlerlik.

Keywords: Computer aided architectural design, computer aided structural design, building information modeling, interoperability. sayesinde, biçimde yapılan düzeltmeler bilgisayar programları yardımıyla taşıyıcı sistem tasarımına kolaylıkla ve hızlıca yansitılabilmekte, taşıyıcı sistemdeki herhangi bir iyileştirmeye göre biçim sıfirdan yaratılmak yerine hızlıca revize edilebilmektedir. Osd mühendislik firmasının kurucularından olan mühendis Harald Kloft'un (2006, s. 253) da 'biçim yaratma (generating a form)" olarak tanımladığ 1 ve inşa edilebilirliğin mimari tasarım sürecine dahil olduğu dijital süreçlerde, karmaşık biçimlerin inşa edilmesine olanak sağlayan taşıyıcı sistem tasarımı, mimari tasarımın başat elemanlarından biri haline gelmiştir. Günümüzde, karmaşık biçimler üretmek ve bu biçimlerle etkileşim içinde çalışabilecek taşıyıcı sistem çözümleri bulabilmek için bazı tasarım firmaları ise özel yazılımlar üretmeye başlamışlardır. Örneğin, Foster and Partners'ın geliştirilirken katkıda bulunduğu Bentley Generative Components yazılımı ile karmaşık geometriye sahip biçimleri tasarlamak ve üretmek amaçlanmıştır. Aynı şekilde, Frank Gehry’nin geliştirdiği CATIA temelli Digital Projects yazılımı da yine karmaşık geometrilere sahip tasarımları analiz etmeyi ve çözümlemeyi amaçlamıştır (Dan ve Bo, 2009, s. 373-376).

Dijital teknolojilerin gelişmesiyle birlikte, 2000'li yılların başlarında Yapı Bilgi Modelleme - YBM (Building Information Modeling - BIM) teknolojisi mimari tasarım ve üretim süreçlerine dahil olmuştur. YBM bilgisayar destekli bir proje çizim aracı olmanın ötesine geçerek yapıyı oluşturan elemanların geometrileri, boyutları, konumu, malzemeleri, özellikleri ve birbirleriyle olan ilişkileri gibi üretim, inşaat ve işletim aşamalarında gerekli olan veriyi içinde barındıran üç boyutlu bir veri modeli ve farklı disiplinlerin tasarımdan üretime tüm sürece dahil olabildiği bir platformdur (Eastman, Teicholz, Sacks ve Liston, 2011). Bu üç boyutlu model disiplinlerarası ortak kullanılabilmekte, bilgi alışverişini daha sağlıklı hale getirmekte ve taşıyıcı sistemin biçim ile eşzamanlı gelişmesini desteklemektedir. Dijital tasarım, dijital yaratma ve üretme süreçlerini içeren süreç odaklı bir yapıya dönüşmekte ve bugün dijital mimari tasarım sürecini değerlendirebilmek, taşıyıcı sistem tasarımını da anlamayı gerektirmektedir.

Bu çalışma, dijital teknolojilerin mimari tasarım süreçlerinde kullanımı ile mimari tasarımın taşıyıcı sistem tasarımı ile değişen ilişkisini ve biçim ve taşıyıcı sistem kararlarının birbirleri üzerindeki etkisini tartışmaktadır. Yeni dijital tasarım ve üretim teknolojileri, tasarımcılara ve mühendislere yeni olanaklar ve potansiyeller sunmuş, bu potansiyeller birçok yazar tarafindan ele alınmış ve çeşitli tasarım süreçlerinde yer almıştır. Bu çalışmada, taşıyıcı sistem tasarımının dijital mimari tasarım sürecinin bütünleşik bir parçası haline gelmesi, biçim-taşıyıcı sistem-inşa edilebilirlik arasındaki ilişki bağlamında irdelenmiştir. $\mathrm{Bu}$ irdelemede, karmaşık geometrilerin tasarımını, analizini ve inşasını olanaklı kılan bilgisayar destekli tasarım $(B D T)$, ve eşzamanlı bir etkileşimi mümkün hale getirerek entegre süreci destekleyen YBM süreçleri, BDT ve YBM'nin inşa edilebilirlik sürecine olan katkısı ve BDT ve YBM ilişkisinde tasarım sürecinin geldiği nokta değerlendirilmektedir. Bu amaçla, çalışma bilgisayar destekli tasarımda ve yapı bilgi modellemede taşıyıcı sistem tasarımı olarak iki ana başlık altında toplanmıştır. BDT ve YBM'nin mimari tasarım ve taşıyıcı sistem tasarımı arasındaki ilişkiye olan etkisi, entegre tasarım süreçlerine sahip örnekler ve süreçlerde kullanılan araçlar üzerinden tartışılmıştır.

\section{Bilgisayar Destekli Mimari Tasarım Süreci ile Entegre Taşıyıcı Sistem Tasarımı}

1960'larda, dijital teknolojiler mimarlik disiplininde kullanılmaya başlanmıştır. 1982 yilında Autodesk firmasının piyasaya sürdüğ̈ AutoCAD ve 1985 'te BentleySystems'in piyasaya sürdüğ̈̈ Microstation gibi programlar, tasarımcılar tarafından çizim aracı olarak kullanılmaya başlanmış ve dijital teknolojiler tasarım süreçlerinde yer almaya başlamıştır. Tasarımcılar bu programları projelerini iki boyutlu temsil etme amaçlı kullanmışlardır. Dijital teknolojinin gelişmesiyle, 3 boyutlu modelleme imkanı olan Robert McNeel \& Associates'in pi- 
yasaya sürdüğü Rhinoceros ve CATIA gibi programlar ile mimarlar, iki boyutlu çizimlerin temsillerine ek olarak, tasarımlarının üç boyutlu modellerini de oluşturmaya başlamışlardır. 1990'larda, bazı bilgisayar destekli programlar tasarım süreçlerinde bir temsil aracı olmanın ötesine geçerek, tasarım ortamı haline gelmişlerdir. Özellikle 2008'de Rhinoceros programı üzerinde çalışan Grasshopper yazılımı, sonuç üründen öte sürecin tasarlanmasına olanak veren bilgisayar destekli tasarım programlarından biri olmuş ve böylece dijital teknolojiler, tasarım fikrinin oluşturulması aşamasından itibaren tasarım ve üretim süreçlerine dahil olmaya başlamışlardır. Tasarımcilar bilgisayar programlarını tasarım sürecinin sonunda sadece temsili çizimlerin üretilmesi amacıyla bir araç olarak kullanmak yerine, dijital tasarım platformu olarak kullanmış ve dijital teknolojiler tasarımın erken evresinden itibaren tasarım süreçlerine dahil olmuştur. Bilgisayarların değişen rolü, hem mimari tasarım sürecini hem de sürecin taşıyıcı sistem tasarımı ile olan ilişkisini değiştirmiş ve geliştirmiştir.

Bilgisayar destekli tasarım ve üretim mimarlara, karmaşık bilgisayar programlarını kullanmadan hayal etmesi imkansız olan Öklid-dışı karmaşık eğri yüzeyleri ve biçimleri kolayca tasarlama, temsil etme ve inşa etme gücü vermiştir. Ayrıca mimarların bilgisayar destekli tasarım süreçlerinde kullandığı programlardan olan Softimage, 3D Studio Max, CATIA, Alias ve Maya, mimari tasarım amaçlı geliştirilmemişlerdir. Bu programlar öncelikli olarak uçak endüstrisi, otomotiv endüstrisi, denizcilik endüstrisi ve film endüstrisi gibi endüstriler için geliştirilmiş ve daha sonra mimarlık disiplininde kullanılmaya başlanmışladır. Bunun sonucu olarak nasıl film endüstrisinde yuvarlak formlarla animasyon karakterleri modelleniyorsa ya da otomotiv endüstrisinde eğri yüzeyler ve formlar araba modellemek için kullanıl1yorsa, aynı Öklid-dışı karmaşık biçimler tasarımcılar tarafından mimari tasarım süreçlerinde de üretilmeye ve kullanılmaya başlanmıştır (Imperiale, 2000, s. 38-39; Lynn ve Gage, 2010).
Tasarım süreçlerinde, mimarların bu karmaşık geometriye sahip biçimlerle çalışmaları, mühendisleri yapısal ve biçimsel gereksinimleri karşılayan ve planlanan bütçenin sınırlarında kalan uygun yapısal çözümler bulma konusunda zorlamıştır. Bagneris ve diğerlerinin (2008) çalışmalarında vurguladığı gibi;

"Esnek formlar esas olarak çift eğrilikli yüzeyler ile biçimlendirilmektedir. Ancak bu sadece biçimsel bir kaygı ve geometrik bir tanımlamadır. Mekanik ve hatta teknolojik çözümlerin ele alınması gerektiğinde sorunlar ortaya çıkmakta ve mühendisler, kabusla sonuçlanabilecek zor problemleri çözmek zorunda kalmaktadırlar" (s.85).

Frank Gehry'nin MARta Herford Müzesi projesinde benzer bir durumla karşılaşılmıştır. Binanın formu sadece estetik kaygılarla ortaya çıkan karmaşık bir geometriye sahiptir, ve yük dağılımlarının hesaplanmas1 ve biçim ile birlikte çalışan bir taşıyıcı sistem tasarlanması mümkün olamamıştır. $\mathrm{Bu}$ nedenle mühendisler eğrisel yüzeylerden oluşan biçimden tamamen bağımsız ortogonal geometriye sahip olan bir taşıyıcı sistem tasarlamak zorunda kalmışlardır (Bagneris ve diğerleri, 2008, s. 79-87).

Biçimsel arayışların, mimari tasarım süreçlerinde kullanılan bilgisayar programları aracılığı ile giderek artması, bu arayışlar sonucu elde edilen ürünlerin inşa edilebilirliğinin sorgulanmasını da beraberinde getirmiştir. Bu durum da taşıyıcı sistem tasarımının erken tasarım fikri oluşumundan başlayıp üretime uzanan süreçte biçim tasarımı ile entegre yürütülmesi gerekliliğini açıkça göstermekte ve vurgulamaktadır. Yük analizleri, taşıyıcı sistemin eleman uzunlukları, büyüklükleri ve detay çözümlerine kadar detaylı analizlerin daha biçimin tasarım aşamasında yapılması gerekmekte ve gerektiğinde taşıyıcı sistem kararları biçimin geometrisinde değişikliklere yol açabilmektedir. Dijital teknolojilerin taş1yıcı sistem tasarımına dahil olmasıyla da karmaşık biçimlerin taşıyıcı sistem tasarımı ve analizi kolaylaşmakta, analiz sonuçlarının biçim üzerindeki etkilerinin modellenebilmesi, ve biçimin bu sonuçlara göre modifiye edilme süreci hızlanmaktadır. 
Bilgisayar destekli tasarım sürecinde, biçim tasarımı, taşıyıcı sistem tasarımı, malzeme kararları, elemanların üretimi ve inşa süreçlerinin bütünleşik olduğu bir süreç yürütülmektedir. Süreç bir bütündür ve taşıyıcı sistem tasarımı kendiliğinden onun bir parçasıdır. Kevin R. Klinger'in (2008, s. 36) vurguladığ1 gibi, "analiz, simülasyon, üretim ve montaja dair bilgi mimari üretimde erken aşamalardan itibaren sürece dahil olur." Taşıyıcı sistem analizi ve optimizasyonları biçim başta olmak üzere dijital tasarım sürecinde diğer tüm değişkenlerde değişikliklere ve güncellemelere neden olabilmekte ve böylece taşıyıcı sistem tasarımı tasarım fikrinden inşaya kadar olan tüm dijital sürece dâhil olmaktadır. Bu tip bir yaklaşımda, taşıyıcı sistemin herhangi bir yük veya dış etkinin altında nasıl davranacağı analiz edilebilmekte ve analiz sürecinden elde edilen verilere göre tasarıma bütüncül ya da parçacıl olarak müdahale edilebilmektedir. Bu tasarım süreci, modelleme ile analizlerin birlikte yürütüldügü dijital bir süreçtir.

\subsection{Bilgisayar Destekli Mimari Tasarım Süreci ile Entegre Tașıyıcı Sistem Tasarımı: Araç ve Modeller}

MoSS, GENR8, ParaGen gibi bilgisayar destekli programlar aynı ortamda hem biçim hem taşıyıcı sistem kararlarının birlikte alınmasına imkan vererek, biçim ve taşıyıcı sistemin hesaplanabilir birlikteliğini sağlamıştır. Biçim ile böylesi bir birliktelik ve etkileşim aracılığıly inşa edilebilir kılınan taşıyıcı sistemler, bir taraftan biçimin kıvrılan ve bükülen düzensiz geometrisi ile bütünleşmekte, aynı zamanda bu bütünleşme statik gerekliliklere de cevap verebilmektedir. Böylece, karmaşık biçime sahip olan taşıyıcı sistemler mühendisliğin geleneksel kolon-kiriş mantığında çözümlenen dik açılara sahip ortogonal geometrilerinin dışına çıkmakta ve formun sahip olduğu düzensiz biçimlere sahip olmaktadırlar. Düzensiz biçime sahip bu taşıyıcı sistemler de aynı zamanda bunun bir sonucu olarak farklı uzunlukta, kalınlikta ve boyutta elemanlardan oluşmakta ve her bir farklı elemanın boyutu bilgisayar destekli tasarım sayesinde kolayca hesap- lanıp modellenebilmektedir. Aynı zamanda aynı ürünün çok sayıda üretildiği seri üretim süreçlerinden farklı olarak, bilgisayar destekli parçaya özel üretim teknolojileriyle de bu farklı parçaların üretimi kolaylıkla sağlanmaktadır (Kolarevic, 2009, s. 29-54). Bu bölümde, öncelikle iki boyutlu çizim aracı olmanın ötesine geçerek biçim ile entegre karmaşık taşıyıcı sistemler üretebilen ve daha sonra da bu sistemleri analiz etmede kullanılabilen Tekla Structural Designer, ve GSA: Structural Analysis and Design Software gibi bilgisayar destekli programlara ve çalışma prensiplerine değinilmiştir. Emergent Design Group'tan mimar Peter Testa ve Devyn Weiser'in (2002, s. 13-16) geliştirdiği $M O S S$ ve GENR8 programları kıvrılan ve bükülen yüzeyler üretmekte kullanılan, ve malzeme ve taşıyıcı sistem kararlarının dijital mimari tasarım sürecinde birlikte ele alınabildiği programlardan bazılarıdır. Bu programlar AliasWavefront Studio, Maya gibi tasarım ve modelleme yapılabilen ortamlarla birlikte etkileşim içinde çalışabilmektedirler. Programa, taş1yıcı sistemin geçmesi gereken açıklık, tasarım alanı sınırları, rüzgar yönü, uzunluk, yükseklik, eleman sayısı gibi birçok farklı girdi girilerek ve bu girdiler arasındaki ilişkiler belirli kurallar yardımıyla modellenerek programın tasarımcının istekleri doğrultusunda bir sistem üretmesi sağlanabilmektedir. Michigan Üniversitesi, Hydra Lab'da geliştirilen ParaGen (Von Buelow, 2012, s. 271-284) de erken tasarım evresinde mimari tasarım kararları ve taşıyıcı sistem performans kriterlerine göre tasarımciya çözüm alternatifleri sunan yöntemlerden biridir ve bunu Non-Destructive Dynamic Population Genetic Algorithm (NDDP GA) algoritması kullanarak yapmaktadır. Böylece biçim ve taşıyıcı sistem tasarımı sürece erkenden dahil olmakta ve hem mühendislik hem de mimari tasarım kararlarını karşılayan bir sonuç ürün elde edilmiş olmaktadır.

MoSS, GENR8 ve ParaGen programlarının sahip olduğu bir diğer özellik de sisteme girilen girdilere uyan birden fazla alternatif üretebilmeleridir. Bu alternatifler geleneksel kağıt üzerindeki yaklaşımlara göre çok 
daha kısa sürede üretilebilmekte ve kolayca analiz edilebilmektedir. Bu alternatiflerden hangisinin en iyi olduğunu seçmek tasarımcıya bağlı olabilirken, bilgisayar destekli olarak da gerçekleşebilmektedir. Sonuçları değerlendirecek matematiksel bir fonksiyon üreterek, programın sonuçlar arasından hangisinin en uygun kriterlere sahip olduğunu belirlemesi sağlanabilmektedir. Örneğin ParaGen yönteminde, belirlenen mimari ve teknik performans kriterlerine göre üretilen geometriler arasındaki en iyi sonuçları filtreleyen bir algoritma kullanılmaktadır (Von Buelow, 2012, s. 271-284). Bilgisayar destekli eleme yöntemi süre açısından daha avantajlı olsa da yaratıcılık ve estetik yönünden değerlendirme matematiksel olarak tanımlanamamaktadır. $\mathrm{Bu}$ yüzden tasarımcının devreye girip, kendi estetik kaygılarına göre seçim yaptığı durumlar da görülebilmektedir (Hemberg, O'Reilly ve Nordin, 2001, s. 160-167).

Bilgisayar destekli taşıyıcı sistem analizinde ise Graphic statics, Evolutionary Shape Optimizer, Structural Analysis Modelling, ANSYS Design Space, Tekla Structural Designer, EESO (extended evolutionary structural optimization), GSA: Structural Analysis and Design Software gibi birçok program ve yöntem kullanılmaktadır. Bu program ve yöntemlerin tasarım sürecine entegre edilmesiyle taşıyıcı sistem tasarımı ve analizi kolaylaşmakta ve analiz sonuçlarının mimari tasarıma geri besleme süreci de hızlanmaktadır. Örneğin, Graphic statics mimar ve mühendisler tarafindan kullanılan, taşıyıcı sistemdeki yük dağılımını analiz ederek daha az malzeme ve minimum üretim maliyeti ile üretim yapmayı hedefleyen bir taşıyıcı sistem optimizasyon yöntemidir. Dijital teknolojilerin taşıyıcı sistem tasarım ve optimizasyonlarında kullanılması üzerine çalışmaları bulunan mimar Lorenz Lachauer ve araștırmacı Toni Kotnik (2010, s. 193-203), taşıyıcı sistem tasarımlarında sistemdeki yük dağılımını analiz etmek için Graphic statics metoduyla çalışmışlardır. Kotnik daha sonra bu metodu parametrik modelleme yapmaya olanak veren bir programlama dili ve ortamı olan Grasshopper ile entegre ederek hem mimarın tasarım kararlarını hem de taşıyıcı sistem tasarımını birlikte ele almıştır. Massachusetts Institute of Technology üniversitesinde çalışılan Digital Structures adlı araştırma projesinde ise, mimari önceliklerin ve taşıyıcı sistem prensiplerinin erken tasarım evresinde entegre bir süreçte gelişmesi amaçlanmıştır. Dijital teknolojilerin ve araçlarının bu işbirlikçi sürece katkısı da çalışma alanları arasındadır. Böylece, tasarlanan biçimin sonradan bir analiz programına aktarılmasının yerine, biçimin taşıyıcılığının tasarımın erken evrelerde anlaşılması ve hesaba katılması amaçlanmıştır (Digital Structures and MIT, 2015). Structural Morphology (SMG) of the International Association for Shell and Spatial Structures (IASS) birliği tarafından desteklenen Computation and Geometry çalışma grubu da araştırmacıların, mimarların ve mühendislerin birlikte çalışabileceği ve farklı disiplinlerden bilgi paylaşımı yapılabileceği entegre bir platform geliştirmeyi amaçlamışlardır (Van De Straat, Shepherd ve Winslow, 2011).

Modelleme ve analiz amaçlı kullanılan bilgisayar destekli tasarım araçları arasındaki veri transferi, biçim ve tașıyıcı sistem tasarımı birlikteliğinde önemli bir rol oynamaktadır. Böylece, sadece modelleme fonksiyonu olan ve sadece analiz fonksiyonu olan araçlar arasındaki etkileşim büyük önem kazanmıştır. Örneğin Maya, CATIA, Generative Components ve Rhinoceros gibi üç boyutlu modelleme ortamlarında tasarlanan biçimler daha sonra Evolutionary Shape Optimizer, Structural Analysis Modelling, ANSYS Design Space, Tekla Structural Designer, GSA: Structural Analysis and Design Software gibi programlara aktarılabilmekte ve burada taşıyıcı sistemin gerilme, burkulma, basınç, yük dağılımı gibi statik ve dinamik analizleri yapılabilmektedir. Yapılan analizler sonucu gerek görülen yerlerde biçim modifiye edilebilmekte ve böylece taşıyıcı sistem analizi sonuçlarının biçimin son halini almasına katkı sağladığı gözlemlenebilmektedir. Yani halihazır tasarlanan bir biçim, sürecin başında belirlenen taşıyıcı sistem performans hedeflerine ve yapilan analizlere uymak için süreçte deformasyonlara maruz kalabilmektedir. Her ne kadar taşıyıcı 
sistem kararları erken mimari tasarım fikri oluşumu aşamasının bir parçası olmasa da, tasarım sürecine entegre olmakta ve biçimin yapısal performansını iyileştirmek ve rijitliğini arttırmak gibi nedenlerle biçim optimize edilmekte ve biçimin geometrisinde iyileştirmeler yapılabilmektedir. Ve sonuç olarak mühendislik disiplininin prensipleri, uzmanlığı ve yaratıcılığı, mimari tasarım kaygıları ve estetik ile bilgisayar destekli programlar aracılığıyla bir araya gelmiş olmaktadır (Kloft, 2006, s. 248-255). Örneğin Peter Cook ve Colin Fournier'in Avusturya'da bulunan Kunsthaus Graz projesinin tasarım sürecinde Rhinoceros ortamında tasarlanan biçimin performans analizleri için, yük dağılımı ve yerçekimi gibi fiziksel etkiler altındaki stres dağılımı analizleri yapmakta kullanılan Finite Element Analysis yöntemi kullanılmıştır. Analiz sonuçlarına dayanarak, yapısal performansı iyileştirmek ve rijitliği arttırmak için biçimin eğriliği arttırılmıştır (Resim 1) (Fournier ve Cook, 2003; Kloft, 2006, s. 248-255; Kolarevic, 2005).

\subsection{Bilgisayar Destekli Mimari Tasarım Sürecinde Taşıyıcı Sistem Kararları}

Bilgisayar destekli mimari tasarım süreçlerinde dijital araçların kullanımının neden olduğu değişimi, tasarım düşüncesinin oluşumunu ve mimari tasarım süreci ile entegre taşıyıcı sistem tasarımını, bu süreç ile üretilen ve inşa edilen yapılar aracıllı̆ ile analiz etmek, süreçteki bütünleşikliğin nasıl sağlandığını anlamak açısından önemlidir. İncelenecek yapılar, taşıyıcı sistem mühendisi Mutsuro Sasaki'nin taşıyıcı sistem tasarımı ve analizlerinde rol aldığ 1 yapılardan seçilmiştir. Sasaki, Toyo Ito ve Arata Isozaki'nin de dahil olduğu birçok mimarla uzun yıllardır birlikte çalışmıştır (Sasaki, Ito ve Isozaki, 2007) ve bu uzun çalışma süreci mimari tasarım ile taşıyıcı sistem tasarımı ilişkisinin dijital süreçteki entegrasyonunu destekler niteliktedir. Bu bölümde Sasaki'nin Arata Isozaki ile çalıştığı Qatar Education City Convention Centre ve Toyo Ito ile çalıştığ Island City Central Park projelerinin tasarım yaklaşımları incelenecektir. Arata Isozaki'nin 2011 de kullanıma açılan Qatar Education City Convention

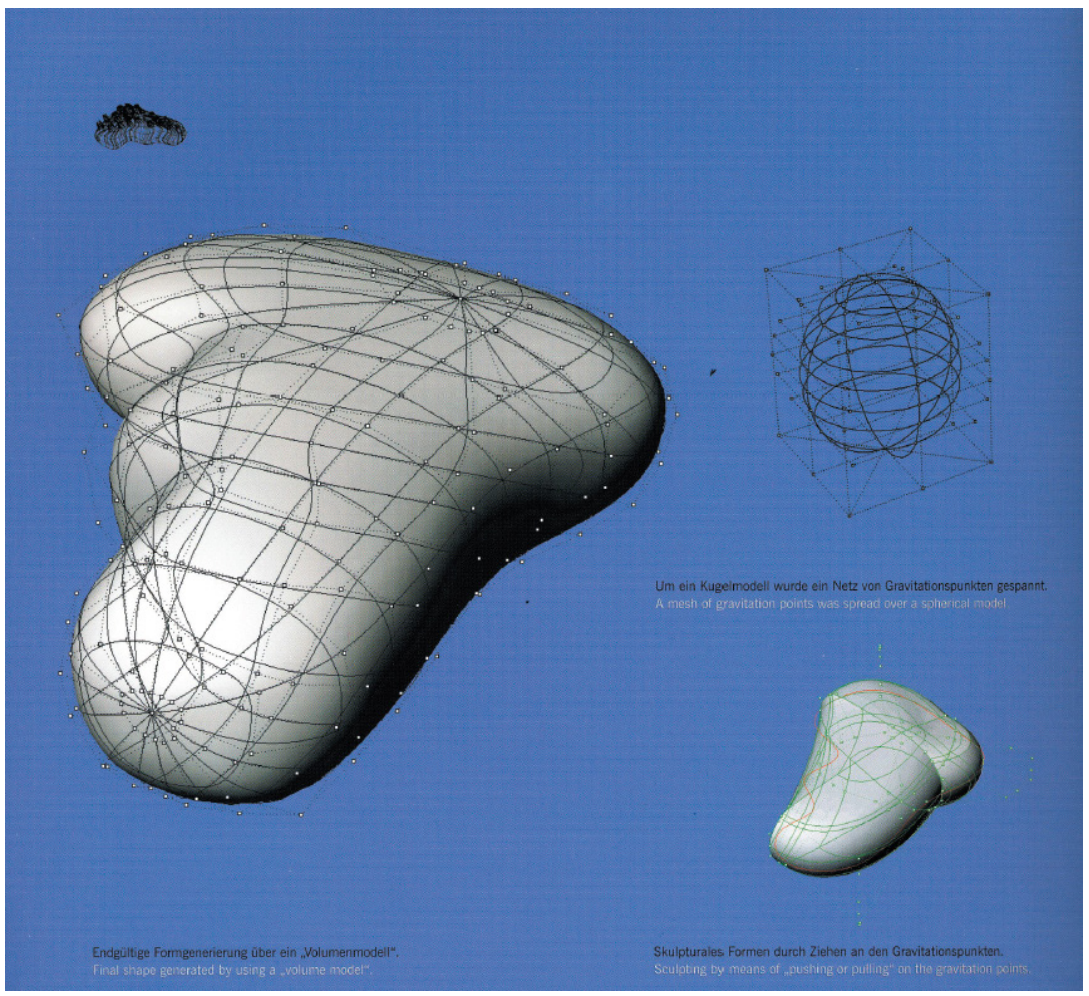

Centre binasının girişi için tasarladığ 1 ağaç görünümlü yapı, biçim, malzeme ve taşıyıcı sistem kararlarının birarada alındığı bütünleşik bir sürecin ürünüdür. Mühendis Buro Happold ile işbirliği içinde geliştirilen ağaç biçimli organik yapı, hesaplamalı mühendislik yöntemlerinin süreç içinde kullanılmasıyla nihai biçimine ulaşmıştır. Süreçte, Sasaki'nin Extended Evolutionary Structural Optimization (EESO) optimizasyon yaklaşımı kullanılarak yük dağılımları hesaplanmış, geometri optimize edilmiş ve en az malzeme kullanılarak üretilebilecek en verimli çalışan biçim elde edilmiştir. Minimum malzeme kullanılması amaciyla ayn zamanda finite element analysis analiz yöntemi de kullanılmış ve biçimin taşıyıcılığı analiz edilerek, taşıyıcılık işlevi olmayan kısımlar biçimden çıkarılmıştır. Resim 2'de biçimin belirlenen tasarım ve taşıyıcı sistem kararları girdileri göz önüne alınarak EESO optimizasyon metodu ile nasıl evrildiği gösterilmektedir (J. Burry ve M. Burry, 2010, s. 130; Naboni ve Paoletti, 2018, s. 69-92).

Toyo Ito'nun 2005 yılında inşaatı tamamlanan Japonya' daki Island City Central Park projesi, modelleme ve analiz fonksiyonları-
Resim: I

Biçimin taşıyıcı sistem analizlerine göre deforme edilme süreci (sağ) ve sürȩ sonunda elde edilen biçim (sol) (Fournier ve Cook, 2003, 5. 30). 
Resim: 2

EESO optimizasyon metodu ile biçimin evrilme süreci, latar Education City Convention Centre, Arata Isozaki (Kaynak: J. Burry ve M. Burry, 2010, 5. 130).
Resim: 3

Biçimin taşıyıcı sistem analizleri ışı̆̆ında deforme edilme süreci, Island City Central Park, Toyo Ito \& Associates (Kaynak: J. Burry ve M. Burry 2010, s. 138).
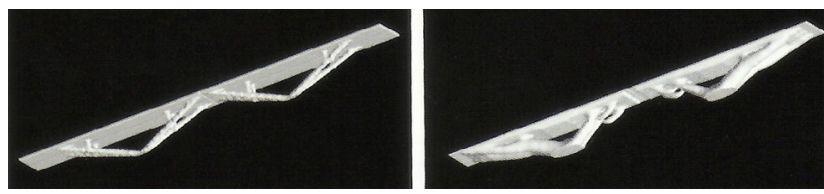

na sahip ayrı programların kullanıldığı bir süreçte gelişse de taşıyıcı sistem ve biçim tasarımının birlikteliğini örnekler nitelikte bir tasarım sürecine sahiptir. Arazinin bir parçasıymış gibi görünmesi amaçlanan ve araziye yayılan eğrisel ve organik bir geometriye sahip olan biçim analiz edilmiş ve sonuçlara göre ana tasarım fikrinden kopmadan biçim geometrisi üzerinde iyileştirmeler yapılmıştır. Yapılan analizler ve optimizasyonlar sonucunda biçimin hangi durumda yüzey gerilimlerini en iyi taş1yabileceği saptanmış ve buna bağlı olarak Resim 3'te görüldüğü üzere aynı biçimin farklı geometriye sahip olası varyasyonları elde edilmiştir. Evolutionary Shape Optimizer yöntemi ile de bu varyasyonlar arasından en büyük hacmi en az malzeme kullanımı ile örten en ideal sonuç seçilmiş ve tasarım süreci sonunda hem mekanik hem de tasarım ihtiyaçlarına cevap veren bir biçim elde edilmiştir (J. Burry ve M. Burry, 2010, s. 138-140).

Her ne kadar bilgisayar destekli programların kullanıdığı tasarım süreçlerinde veri paylaşımı ile entegre bir yaklaşım olduğundan bahsedilse de, çoğunlukla proje katılımcılarının kendi alanına özgü programlarda uzmanlaşması, katılımcılar arasındaki iletişim güçlüğü, kullanılan programların uyumsuzluğu ve verinin bir programdan diğerine aktarılma gerekliliği işgücü ve zaman kayıplarına neden olmaktadır. Dijital teknolojilerin gelişmesiyle mimari tasarım, üretim ve işletim süreçlerinde kullanılmaya başlanan Yapı Bilgi Modelleme, bilgisayar destekli programların kullandığı dosya tabanlı veri depolama yöntemleri yerine veriyi tüm katılımcıların ulaşabileceği ortak bir platformda depolayarak tasarım

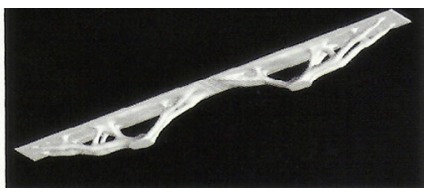

sürecinin eşzamanlı ve işbirlikçi ilerlemesini sağlamakta ve tasarım sürecindeki disiplinlerarası etkileşimi desteklemektedir (Eastman ve diğerleri, 2011, s. 15-17).

\section{Yapı Bilgi Modelleme Süreçlerinde Mimari Tasarım Süreci ile Entegre Taşıyıcı Sistem Tasarımı}

2000'li yılların başlarından günümüze kullanılan Yap1 Bilgi Modelleme (YBM) teknolojisi, bir tasarımı sunmak, modellemek veya bu tasarımın sistem analizlerini yapmak için kullanılan bilgisayar destekli bir araç olmanın ötesinde, entegre bir ürün ve süreç modeli olmasıyla, bilgisayar destekli tasarımdan farklılaşmaktadır (Laakso ve Kiviniemi, 2012, s. 134-161). YBM, tasarımdan başlayarak, taşıyıcı sistem tasarımı, analizi, üretimi ve projenin inşasına uzanan süreçte, farklı disiplinleri ilgilendiren tüm proje verilerini dijital formatta entegre bir şekilde toplamakta ve yönetmektedir. Böylece mimari tasarım ile taşıyıcı sistem tasarımı arasındaki entegre süreci desteklemekte ve disiplinlerarası ortak bir çalışma ortamı sağlamaktadır.

YBM'nin nesne yönelimli yapısı sayesinde, dijital ortamdaki mimari tasarım 2 boyutlu bir çizim olmaktan çıkıp tasarım elemanlarının boyut, geometri ve malzeme gibi özelliklerini ve diğer elemanlarla olan ilişki verilerini içinde barındıran 3 boyutlu bir modele dönüşmüştür. Duvar, kapı, döşeme, çatı gibi tasarım elemanlarını nesne olarak barındırmayan, bu elemanların verisini sadece çizgilerden oluşan iki boyutlu bir geometri olarak tutan programlarda bilgi aktarımı sorunludur. Örneğin, Autocad gibi nesne tabanlı olmayan bir bilgisayar destekli programda duvar, aslında çizgilerden
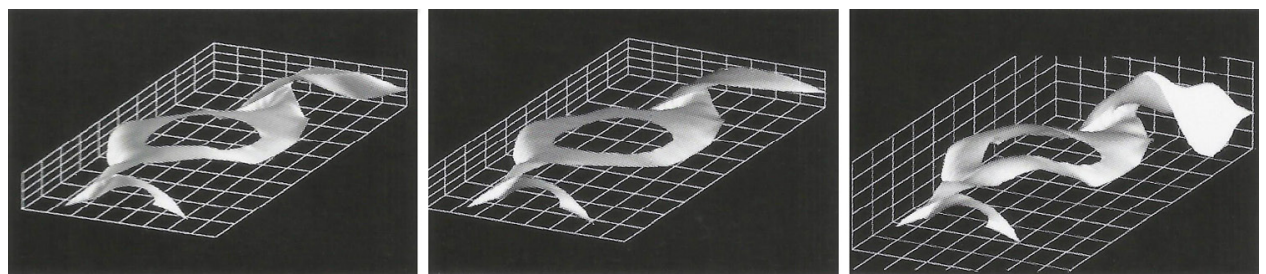
oluşan iki boyutlu bir geometridir ve başka bir program bu çizimin bir duvar nesnesi olduğunu algılayamamaktadır. YBM burada devreye girip, her program tarafindan aynı yorumlanan ve anlaşılan nesnelerden oluşan bir model oluşturmaya firsat vermektedir. Böylece, mimarın dijital ortamda modellediği döşeme, mühendis tarafından yürütülen taşıyıcı sistem tasarım ve analiz süreçlerinde de döşeme olarak var olmaktadır. Ayrıca YBM ortamında üretilen plan, kesit gibi çizimler, bilgisayar destekli tasarım programlarında olabileceği gibi birbirinden bağımsız olarak üretilmemekte, herhangi bir ekranda yapılan bir değişiklik diğer tüm plan, kesit, görünüş, detay çizimlerinde ve üç boyutlu modelde de eş zamanlı güncellenmektedir. Böylece hem program içindeki koordinasyonu, hem de mimar ve mühendisin kullandığı farklı programlar arasındaki koordinasyonu sağlayan YBM bütünleşik ve eşzamanlı ilerleyen tasarım süreçlerinin ortaya çıkmasını sağlamaktadır.

Veri aktarımını anlamlı hale getiren YBM, aynı zamanda bir süreç modeli olarak çalışarak ve mimar, mühendis, iş veren gibi tüm proje katılımcıları arasındaki iletișimi arttırarak proje sürecini hızlandırmaktadır. YBM'den önceki zamanlarda, mimar, mühendis gibi proje katılımcılarının süreç içerisindeki bilgi alışverişleri mekan ve zamana bağlı olarak kısıtlı olmaktaydı. Her katılımciya uyan bir zamanda bir araya gelmeye çalışmak, tasarım sürecinin uzamasına ve zamanın verimli kullanılamamasina neden olmaktaydı. Ayrica, projede yapılan her bir değişiklik sonucu biraraya gelip değişiklikleri tartışma ve revizyonlara göre tasarımın tekrar çizilmesi gereksinimleri maliyet ve iş gücünün de artmasına neden olmaktaydi. Dijital teknolojilerin gelişmesiyle, YBM süreci bir çok farklı disiplinden katılımcının tasarım sürecine dahil olmasını sağlamıştır. İnternetin de desteğiyle, katılımcılar arası bilgi alışverişi ve fikir paylaşımı zaman ve mekana bağlı olmaksızın hızlanmış ve kolaylaşmıştır. Tüm katılımcıların veriye eşzamanlı ulaşabilme imkanı, katılımcılara hataları ve sorunları anında tespit edebilme ve zamanında müdahale edebilme imkanı vermiştir. Tasarımdan üretime uzanan sü-

reç de böylesi bir iletişim ortamında, ortak çalışmalar sayesinde hızlanmıştır (Akipek ve Inceoğlu, 2007, s. 237-253).

\subsection{Yapı Bilgi Modelleme Süreçlerinde Mimari Tasarım Süreci ile Entegre Taşıyıcı Sistem Tasarımı: Araç ve Modeller}

Gelişmekte olan bilgisayar teknolojileri ve YBM, tasarımcılar arasında bilgi alışverişine olanak sağlayarak mimar ve mühendis gibi birçok farklı disiplinden uzmanı sürece dahil etmiştir. Aynı zamanda tüm proje verilerini dijital formatta tek bir modelde toplayarak hem farklı disiplinlerin hem de aynı disiplin içerisinde kullanılan farklı amaçlardaki programların iletişimini sağlamıştır (Resim 4). Graphisoft'un Archicad program1, Autodesk firmasının Revit, Revit Structure, ve Revit MEP programları, BentleySystems' in Open Buildings programı ile Tekla firmasının Tekla Structures programı işbirlikçi YBM süreçlerinde kullanılan programlara örnek olarak verilebilir. YBM süreçleri sağlkklı bir veri alışverişi için sadece farklı disiplinler arasındaki işbirliğini değil, farklı yazılım firmalarının ürünlerini ve veri modellerini kullanan mühendis ve mimarların arasındaki veri aktarımını da desteklemelidir. Farklı programlar ya da veri modelleri kullanıldığında projenin transfer edilecek programa uygun bir formata dönüştürülmesi gerekmekte ve bu dönüşümler sırasında veri kaybı, verinin yanlış eşleşmesi gibi sorunlarla karşılaşılmaktadır. Bu sorunlar, kaybolan verinin sıfırdan modellenmesini ya da yanlış eşleşmenin manüel olarak düzeltilmesini gerektirmekte, bunlar da vakit kaybına ve

Resim: 4

Birlikte islerlik: verinin tek ve ortak bir model ile yönetilmesi.

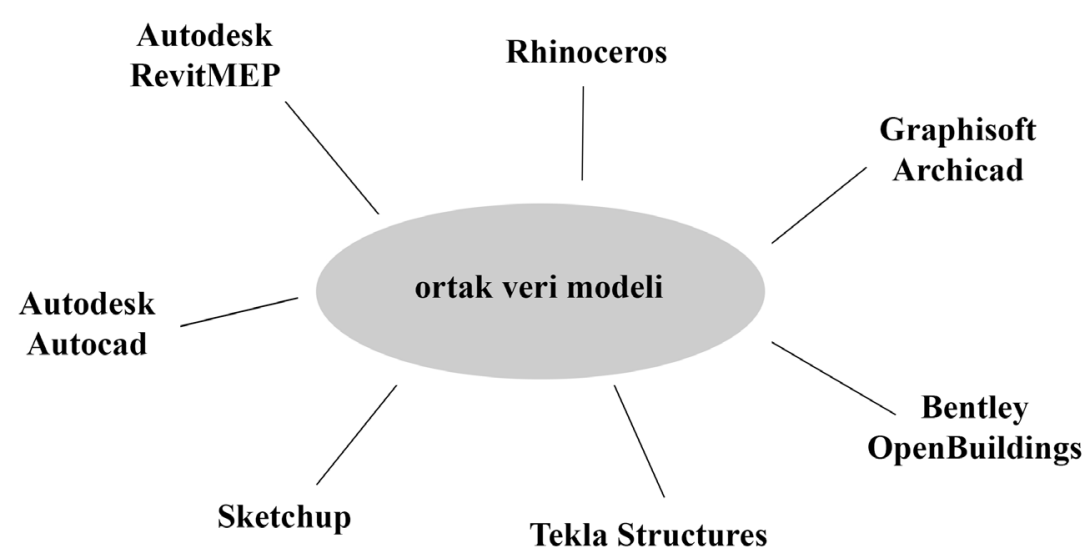


manüel müdahaleden kaynaklı hatalara neden olabilmektedir. Örneğin Autodesk'in 360 BIM Design (Autodesk, 2017b) yazilım1, bu gibi veri kayıplarını engellemek ve $R e$ vit kullanmayan proje katılımcilarıyla olan koordinasyonu, etkileşimi ve veri aktarımını desteklemek için kullanılmaktadır.

Farklı programların eşzamanlı çalışması ve koordinasyonu veri aktarımını desteklediği gibi aynı zamanda herhangi bir programın kısitlı olduğu bir durumda bir diğer programın devreye girip bu amaçla kullanılabilmesini sağlamaktadır. Örneğin, YBM araçları nesne tabanlıdır ve bu araçlar kapı, pencere, döşeme, çatı gibi hazır kütüphane nesneleriyle çizim yapmaya imkan vermektedir. Bu nedenle YBM araçları, karmaşık geometrili biçimler üretmede kullanılan üç boyutlu bilgisayar destekli modelleme yazılımlarının sağladığg özgürlüğü ve esnekliği tasarımcılara verememektedir. Fakat son zamanlarda geliştirilen ve farklı programların veri transferi olmaksızın eşzamanlı çalışmasını sağlayan bağlantılar sayesinde YBM araçlarının bu kısıtlılığının ortadan kalktı̆̆ından bahsetmek mümkündür. Örneğin, Grasshopper-Archicad Live Connection (Bimsoft, 2016) bağlantısı ile YBM süreçlerinde kullanılan programlardan biri olan Archicad, Grasshopper yazılımı ile entegre çalışabilir hale gelmekte, her iki programın da en iyi özelliklerini kullanarak tasarım yapmak mümkün olmakta ve bu durum da üç boyutlu modelleme imkanlar1nı zenginleştirmektedir.

YBM süreçlerinde kullanılan ortak verinin farklı her program ve kullanıcı tarafindan aynı yorumlanmasını sağlamak ve veri kaybını ve yanlış veri eşleşmelerini önlemek için standartlar geliştirilmektedir. $\mathrm{Bu}$ süreçlerde birlikte işlerlik için birçok yazılım geliştiricisinin ortak arayüzler, veri modelleri ve veri şemaları üzerinde anlaşmasi gerekmekte, bu da standartlar yard1mıyla gerçekleşmektedir. buildingSMART firmasının geliştirdiği Industry Foundation Classes $(I F C)$ veri modeli, birlikte işlerlikte önemli bir role sahiptir. Günümüzde IFC, veri aktarımı için en yaygın kullanılan uluslararası YBM standardlarından biridir ve açık kaynaklı olması dolayısıyla herhangi bir firmaya ya da programa özgü değildir (buildingSMART, 2019). Herhangi bir firmaya özgü olmaması da farklı yazılım firmalarının ürünlerini kullanan mühendis ve mimarların birlikte çalışabilmesine katkı sağlamakta, işbirliğini, verimliliği ve üretkenliği arttırmaktadır.

Tasarım fikrinin oluşmasından başlayıp üretim ve inşaaya kadar devam eden süreci kapsayan etkileşimli YBM ortamında, tüm veri bulut tabanlı bir modelde de depolanabilmektedir. Bu modele isteyen katılımc1 istediği zaman bulut üzerinden ulaşabilmekte ve aynı model üzerinde gerekli değişiklikleri ve detaylandırmayı yapabilmektedir. Autodesk' in 360 BIM Design yazılımı ve Graphisoft'un Archicad Teamwork özelliği ortak bir modeli çevrimiçi olarak bulut sisteminde depolayan yazılımlara örnek olarak verilebilir. Böylece inşaat mühendisi, mimarın tasarladığı modelin üzerinde taşıyıcı sistem çözümlerini üretebilmekte, mühendisin öngördüğü değişiklikler mimar tarafından eşzamanlı olarak görülebilmekte ve mimar bu değişikliklere anında tasarımı adapte edebilmektedir. Bu da işbirlikçi ve bütünleşik bir süreç ortaya çıkarmaktadır. Hatta Hamidavi, Abrishami, Ponterosso, Begg ve Nanos'un (2020, s. 149-169) çalışmasında olduğu gibi bu adapte etme süreci otomatikleștirilebilmekte ve belirlenen kurallar dahilinde (iki kolon arası mesafe, maksimum yükseklik $v$ b.) biçimdeki değişiklikler sonucunda taşıyıcı sistem otomatik olarak kendini eşzamanlı güncelleyebilmektedir. Taşıyıcı sistem tasarımının sürece erken dahil olması sayesinde farklı opsiyonlar ve yaklaşımlar da erkenden denenebilmekte, performans ve maliyet analizleri erken tasarım evresinde yapılabilmektedir. Böylece dijital teknolojiler, hem mimari tasarım hem de taşıyıcı sistem tasarımı, analizi ve optimizasyonu süreçlerine dahil olarak karmaşık geometrideki yapıları tasarlamayı ve üretmeyi mümkün hale getirmektedir (Hamidavi ve diğerleri, 2020, s. 149-169).

\subsection{Yapı Bilgi Modelleme Süreçlerinde Taşıyıcı Sistem Kararları}

Taşıyıcı sistemin biçim ile eşzamanlı geliştirildiği ve verinin ortak bir üç boyutlu modelde depolandığı Yapı Bilgi Modelleme 
Resim: 5

Phoenix International Media Center, Pekin (Kaynak: Autodesk, 20I7a). süreçlerini örnekler üzerinden incelemek, birlikte işlerliğin ve farklı disiplinlerin sürece eşzamanlı dahil olmasının bilgi alışverişini ve iletişimi nasıl daha sağlıklı hale getirdiğini anlamak açısından önemlidir. Bu bölümde karmaşık geometrili biçime sahip bir örnek seçilerek, mimar-taşıyıcı sistem mühendisi arasındaki eşzamanlı iletişimin ve YBM kullanımının inşa edilebilirlikteki önemi vurgulanmıştır.

Pekin'de bulunan ve Beijing Institute for Architecture Design (BIAD) tarafindan tasarlanan Phoenix International Media Center (Resim 5) binasının tasarımında karmaşık geometrili bir form ile çalışılmış ve formun inşa edilebilirliği noktasında YBM süreçlerinden yardım alınmıştır. Biçim sürecin başında 3 boyutlu modelleme programları olan Rhino ve Digital Projects yardımıyla modellenmiş ve daha sonra taşıyıcı sistem tasarımı ile üretim ve inşaat aşamalarında kullanılmak üzere yapı bilgi modeli ile çalışılmaya başlanmıştır. Dijital ortamda üretilen üç boyutlu yapı bilgi modeli kullanılarak hem formun geometrisi optimize edilmiş, hem de taşıyıcı sistem kararları bu model kullanılarak mimar ve mühendis arasındaki işbirlikçi yaklaşımla eşzamanlı olarak alınmıştır. Biçim tasarlanırken aynı zamanda yapının rüzgar etkisi altında nasıl davranacağı analiz edilmiş, biçimin geometrisi ile bütünleşen kıvrılan ve bükülen elemanlardan oluşan taşıyıcı sistemin yük analizleri yapılmış ve yapının geometrisi yakın çevredeki binalar üzerinde en az gölgeye neden olacak şekilde optimize edilmiş, böylece hem mimari tasarım kararlarını karşılayan hem de performans kriterlerini sağlayan bir sonuç ürün elde edilmiştir. Aynı zamanda, YBM ile tasarım süreci ve inşa süreci etkin bir şekilde planlanmış, bu planlama ile zamandan tasarruf edilmiş, ayrıca malzeme kullanımı en aza indirilerek maliyet azaltılmıştır. Kısacası, YBM farklı proje katılımciları ve tasarım süreçleri arasındaki iletişimi kuvvetlendirerek işbirlikçi bir süreci desteklemiştir (Dan ve Bo, 2009, s. 373-376; Autodesk, 2017a).

\section{Sonuç}

Dijital teknolojilerin mimarlık disiplininde yer almasıyla birlikte hem tasarım süreçleri ve arayışları değişmiş, hem de mimarlığın diğer disiplinlerle olan iletişimlerinde farklılıklar göze çarpmıştır. Dijital tasarım süreçleri, entegre ve işbirliğgine dayalı bir tasarım yaklaşımını desteklemiştir. Dijital yazılımların mimari tasarım süreçlerinde kullanılmasıyla birlikte, Öklid-dışı karmaşık biçimleri üretmek ve kontrol etmek kolaylaşmış ve hızlanmıştır. Bu karmaşık biçimlerin inşa edilebilirliğini sağlayacak

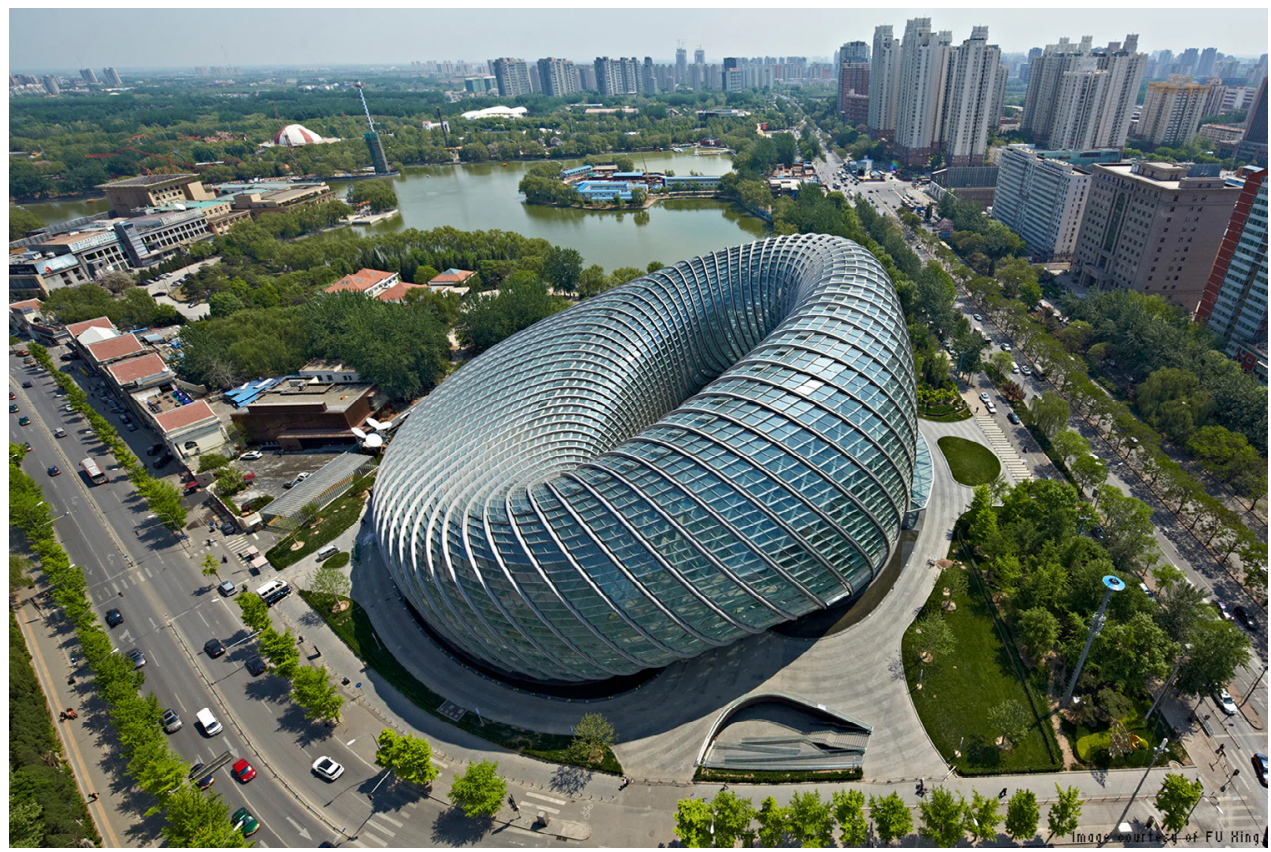


taşıyıcı sistem çözümleri üretmek mühendisleri zorlamış ve bu durum taşıyıcı sistem kararlarının, henüz biçimin ana hatlarının şekillenme evresinde ele alınmasının önemini vurgulamıştır. Dijital teknolojilerin işbirlikçi tasarım süreçlerini desteklemesi ile üretkenlik artmış ve geleneksel ortogonal çözümlere göre daha karmaşık ve lineer olmayan geometriye sahip yaratıcı çözümler üretilebilmiștir. MoSS, GENR8, ParaGen gibi programlar biçim ile taşıyıcı sistemi bir arada ele almaya imkan vererek, mimari tasarımı taşıyıcı sistem tasarımı ile bütünleştirmiştir. Bu entegre süreçte, mimari tasarım ile etkileşim içinde gelişen taşıyıcı sistem de biçimin karmaşık geometrisine uyumlu olmak adına Öklid-dışı geometriye sahip olmuştur. Öklid-dışı geometriye sahip taşıyıcı sistem elemanlarının boyutları da farklılaşmış ve dolayısıyla her biri birbirinden farklı detay çözümleri ortaya çıkmıştır. Tekla Structural Designer ve GSA: Structural Analysis and Design Software gibi bilgisayar destekli programlar, karmaşık geometriye sahip taşıyıcı sistemlerin taşınabilirliğinin analizinde ve hesaplanmasında Graphic statics, Finite Element Analysis ve Extended Evolutionary Structural Optimization (EESO) gibi optimizasyon yöntemleri kullanarak, sistemlerin yük dağılımı, rijitlik, performans ve malzeme analizlerini yapmay sağlamıştır. Bu durum da fiziksel modellerin kullanıldığı manuel yöntemlere göre hesapların ve analiz sonuçlarının mimari tasarıma geri besleme sürecini hızlandırmıştır. Aynı zamanda bilgisayar destekli tasarım programları birçok farklı alternatifi kağıt üzerindeki geleneksel yaklaşımlara göre çok daha kısa sürede üretebilmeye, biçim ile uyumlu çalışabilecek alternatifleri kolayca analiz edebilmeye ve sonuçlara göre alternatifler arasından statik, maliyet ve estetik gibi kriterler göz önüne alınarak en uygununu seçebilmeye imkan vermiştir. Yap1 Bilgi Modelleme ise, Revit Structure, Open Buildings ve Tekla Structures gibi programlarla tüm tasarım ve üretim verisini tek bir modelde toplama, bu modelin her katılımcı tarafindan kullanılabilir olmasını sağlama ve bu modeli kullanarak eşzaman11 tasarım yapmaya imkan verme özellikleri ile ayrıca entegre süreci desteklemiş, karmaşık formların inşa edilebilirlik sürecine katkı sağlamış ve tasarım süreci zaman ve mekandan bağımsız olarak eşzamanlı gelișen bir sürece evrilmiștir. 2000'lerin başlarında YBM teknolojisi ile birlikte dijital programların sadece birer bilgisayar destekli çizim, analiz ve modelleme aracı olarak kullanılmasının ötesine geçilerek disiplinlerarası eşzamanlı iletişimin mümkün olduğu bir süreç tanımlanmıştır. Erken evreden itibaren her katılımcının sürece dahil olması ve verinin ortak bir platformda depolanabilmesi, herhangi bir problemde erken çözüm üretilebilmesine, hataların erken evrede farkedilebilmesine ve gerekli revizelerin anında yapılabilmesine, bu da zamanın daha verimli kullanılmasına katkı sağlamıştır.

Bilgisayar destekli programlar, tasarım sürecinin başından yapı üretimine kadar olan bütünleşik bir süreci desteklemiştir. $\mathrm{Bu}$ kapsamda, taşıyıcı sistem tasarımının bir süreç olarak dijital mimari tasarım sürecinden ayrılamadığı bir duruma gelinmiştir. Yapı Bilgi Modellemenin de gelişmesiyle artık tüm proje katılımcılarının bir arada çalışabildiği, birbirlerinden eşzamanlı geribildirim alabildikleri, sürece müdahale edebildikleri özetle farklı bilgi alanlarına ait analizlerin, müdahalelerin ya da hesaplamaların mimari tasarıma dahil edilebildiği bir süreç vardır. Bu işbirlikçi süreç, projenin planlanan zamanda ve bütçede tutulmasını ve mimar-mühendis arasındaki erken tasarım aşamasından başlayan iletişim sayesinde tasarım kararlarının daha hızlı alınmasını sağlamıştır. Aynı zamanda geliştirilen veri standartları da işbirliğini, verimliliği ve üretkenliği arttırmak için disiplinler arası ortak bir dil tanımlamayı amaçlamıştır. YBM ile çevre, geometri, malzeme, taşıyıcı sistem, boyutlandırma, montaj gibi tasarımdan üretime gereken her türlü bilginin bir arada değerlendirilebildiği karmaşık bütünleşik süreçler tanımlanmıştır. Teknolojinin olanakları ile böylesi süreçler, başlangıçta sadece bilgisayar ortamında kalan karmaşık içerikteki mimari tasarımların üretilebilir hale gelmesini sağlamış ve taşıyıcı sistem tasarımının süreçteki yeri, özel bir inceleme alanı ortaya çıkarmıştır• 


\section{Kaynakça}

Akipek, F. Ö. ve İnceoğlu, N. (2007). Bilgisayar destekli tasarım ve üretim teknolojilerinin mimarlıktaki kullanımları. MEGARON, 2(4), 237-253.

Autodesk. (2017a). A China-based design team gains the insight needed to realize its vision, thanks to intelligent models. Erișim adresi: https://www. autodesk.com/solutions/bim/hub/2016-entry-335

Autodesk. (2017b). BIM 360 design. Erișim adresi: https://www.autodesk.com/bim-360/ design-collaboration-software

Bagneris, M., Rene M., Bernard M. ve Nicolas P. (2008). Structural morphology issues in conceptual design of double curved systems. International Journal of Space Structures, 23(2), 79-87. doi: $10.1260 / 026635108785260560$

Bimsoft. (2016). Rhino - Grasshopper - Archicad bağlantısı. Erişim adresi: https://bimsoft.com.tr/ archicad/algoritmik-tasarim/

buildingSMART. (2019). Industry Foundation Classes. Erişim adresi: https://technical.buildingsmart.org/ standards/ifc

Burry, J. ve Burry, M. (2010). The new mathematics of architecture. London: Thames \& Hudson.

Castle, H. (2010). Editorial. Architectural Design: The New Structuralism-Design, Engineering and Architectural Technologies, 80(4), 5.

Dan, C. ve Bo, S. (2009). On influence of computer modeling technology on architecture design. AsiaPacific Conference on Computational Intelligence and Industrial Applications (s. 373-376) içinde. IEEE. doi: 10.1109/PACIIA.2009.5406580

De Luca, F. ve Nardini, M. (2002). Behind the scenes: Avant-garde techniques in contemporary design. Basel: Birkhäuser.

Digital Structures and MIT. (2015). Agenda. Erișim adresi: http://digitalstructures.mit.edu/\#intro

Eastman, C. M., Teicholz, P., Sacks, R. ve Liston, K. (2011). BIM handbook: A guide to building information modeling for owners, managers, designers, engineers and contractors. John Wiley \& Sons.

Fournier, C. ve Cook, P. (2003). Research outputs 1 and 2: Kunsthaus Graz. UCL Discovery. Erişim adresi: http://discovery.ucl.ac.uk/13132/1/13132.pdf

Franken, B. (2009). Real as data. B. Kolarevic (Ed.), Architecture in the digital age: Design and manufacturing (s. 121-138) içinde. New York: Taylor \& Francis.

Goulthorpe, M. (2009). Scott points: Exploring principles of digital creativity. B. Kolarevic (Ed.), Architecture in the digital age: Design and manufacturing (s.163-180) içinde. New York: Taylor \& Francis.

Hamidavi, T., Abrishami, S., Ponterosso, P., Begg, D. ve Nanos, N. (2020). OSD: A framework for the early stage parametric optimisation of the structural design in BIM-based platform. Construction Innovation, 20(2), 149-169. doi: 10.1108/ CI-11-2019-0126

Hemberg, M., O’Reilly, U. M. ve Nordin, P. (2001). GENR8-A design tool for surface generation. GECCO Late Breaking Papers, 160-167.

Imperiale, A. (2000). New flatness: Surface tension in digital architecture. Springer Science \& Business Media.

Klinger, R. K. (2008). Relations: Information exchange in designing and making architecture. B. Kolarevic ve K. Klinger (Ed.), Manufacturing material effects: Rethinking design and making in architecture (s. 25-36) içinde. New York: Routledge.

Kloft, H. (2006). Structural design of form. K. Oosterhuis ve L. Feireiss (Ed.), Game set and match II on computer games, advanced geometries, and digital technologies (s. 248-255) içinde. Rotterdam: Episode Publishers.

Kolarevic, B. (2000). Digital morphogenesis and computational architectures. Constructing the Digital Space (s. 98-103) içinde. Rio de Janeiro: SIGRADI.

Kolarevic, B. (2009). Digital production. B. Kolarevic (Ed.), Architecture in the digital age: Design and manufacturing (s. 29-54) içinde. New York: Taylor \& Francis.

Kolarevic, B. ve Malkawi, A. M. (Ed.). (2005). Performative architecture beyond instrumentality. New York: Spon Press.

Laakso, M. ve Kiviniemi, A. (2012). The IFC standard: A review of history, development, and standardization, information technology. ITcon, 17(9), 134-161.

Lachauer, L. ve Kotnik, T. (2010). Geometry of structural form. C. Ceccato, L. Hesselgren, M. Pauly, H. Pottmann ve J. Wallner (Ed.), Advances in architectural geometry (s. 193-203) içinde. NewYork: Springer Wien. doi: 10.1515/9783990433713-015

Lynn, G. ve Foster, G. M. (2010). Composites, surfaces, and software: High performance architecture. New Haven, Conn.: Yale School of Architecture.

Naboni, R. ve Paoletti, I. (2018). Architectural morphogenesis through topology optimization. D. D'Uva (Ed.), Handbook of research on form and morphogenesis in modern architectural contexts (s. 69-92) içinde. IGI global. doi: 10.4018/978-15225-3993-3.ch004

Oxman, R. ve Oxman, R. (2010). New structuralism: Design, engineering and architectural technologies. Architectural Design, 4(80), 14-23. doi: 10.1002/ad.1101

Sasaki, M., Itō, T. ve Isozaki, A. (2007). Morphogenesis of flux structure. Aa Publications.

Testa, P. ve Weiser, D. (2002). Emergent structural morphology. Architectural Design: Contemporary Techniques in Architecture, 72, 13-16.

Von Buelow, P. (2012). ParaGen: Performative exploration of generative systems. Journal of the International Association for Shell and Spatial Structures, 53(4), 271-284.

Van De Straat, R. Shepherd, P. ve Winslow, P. (2011). Computation and geometry in structural design and analysis: Proposal for the computation and geometry WG15 study group. Taller, Longer Lighter: Meeting Growing Demand with Limited Resources: IABSE-IASS 2011 içinde. London: Hemming Group Ltd. 